\title{
Magia e cidade: considerações sobre as afinidades entre as práticas mágico-religiosas e o advento da urbanidade no Brasil'
}

\author{
Magic and the city: considerations about the \\ relations between magical-religious practices and \\ the emergence of Brazilian urbanity
}

Gilson Ciarallo

Doutor em Sociologia pela Universidade de Brasília (UnB), professor no Centro Universitário de Brasília, exercendo atividades de pesquisa e ensino em cursos de pós-graduação, Brasília, DF - Brasil, e-mail: gilsonciarallo@gmail.com

\section{Resumo}

O presente artigo tem como objetivo discutir as adaptações das práticas mágico-religiosas ao advento da sociedade urbana brasileira. Coloca-se em perspectiva o pensamento mágico presente na esfera religiosa brasileira, a qual se delineou a fim de ganhar os traços exigidos para a existência no meio urbano. Ao diversificarem-se, tomando formas diversas, as práticas mágico-religiosas passaram a cumprir papéis específicos, mantendo-se em diálogo com as transformações sociais que a urbanização brasileira impôs ao habitante da cidade. Dentre as composições que se foram equacionando contemporaneamente, dá-se atenção especial ao surgimento do mercado de bens de salvação, o qual imprime na esfera religiosa a lógica própria do mercado. Salienta-se que uma das razões das adaptações contemporâneas e da reprodução de práticas mágico-religiosas tão bem ajustadas ao espaço da urbe consiste na singularidade da experiência de modernização brasileira. Tal experiência singular de modernização, por sua vez, é marcada pela dissonância entre o processo de urbanização e os demais processos de transformação social atrelados à racionalização da sociedade ocidental, como o processo de secularização pelo qual passaram as diversas experiências de modernização. Essas reflexões, por sua vez, contribuem para a compreensão da experiência urbana brasileira como uma individualidade histórica dentre outras, nos amplos quadros da modernidade ocidental.

Palavras-chave: Sociologia urbana. Práticas mágico-religiosas. Urbanização. Modernidade ocidental.

\begin{abstract}
The aim of this article is to discuss the adaptations of magical-religious practices to the emergence of Brazilian urban society. The magical thought, which is part of Brazilian religious sphere, is put in perspective, taking into consideration how it developed in order to get the necessary features to exist in the urban scenario. These
\end{abstract}

${ }^{1} \mathrm{O}$ autor é grato aos pareceristas anônimos da revista pelas sugestões enviadas durante os trabalhos editoriais. 
magical-religious practices gained various forms so that they could play specific roles, keeping at the same time the relation with the social transformations that Brazilian urbanization demanded to those who lived in the emerging cities. Special attention is given to the contemporary advent of the market of salvation goods, what gives to the religious sphere the logic of the market. One of the reasons of the contemporary adaptations and reproduction of magical-religious practices, which are so well adapted to the urban scenario, is the peculiarity of the Brazilian modernization experience. Such peculiar experience of modernization is characterized by the dissonance between the process of urbanization and other processes of social change which are part of the rationalization of Western societies, such as the process of secularization that various experiences of modernization passed through. These considerations help to understand Brazilian urbanization as a historical individuality among others within Western modernity.

Keywords: Urban sociology. Magical-religious practices. Urbanization. Western modernity.

\section{Introdução}

Neste artigo procuro lançar luz sobre as relações que se estabelecem entre o advento da urbanidade e os desenvolvimentos próprios do campo religioso na composição social brasileira. Em outras palavras, as reflexões aqui dispostas colocam em perspectiva aspectos da religiosidade brasileira no espaço urbano, os quais se conjugam de forma peculiar em razão de estarem localizadas neste espaço em particular.

Dou atenção especial para o pensamento mágico, o qual parece ter encontrado nas grandes cidades brasileiras lugares propícios para se reproduzir de uma forma específica. Refiro-me a um pensamento mágico que desde a sociogênese do Brasil vem se adaptando às conjunturas diversas e que, uma vez no contexto urbano, ganha dimensões particulares. Uma intuição mantida ao longo das reflexões que estão neste artigo é que essa maneira mágica de pensar, sempre presente na trajetória histórica da sociedade brasileira, desenvolveu-se à maneira dos contornos, das linhas e das dimensões às vezes surpreendentes, suntuosas e por vezes exageradas que o espaço e as maneiras de existir na urbe revelam.

A fim de articular essas reflexões, valho-me da contribuição de Robert E. Park, o qual se utiliza de uma noção de mentalidade mágica elaborada inicialmente nos estudos de Lévy-Bruhl. É também a partir de Park, especificamente o que se refere aos estudos feitos com as ilhas do Caribe acerca das relações entre a mentalidade mágica e a cidade, que delineio algumas das formulações teóricas que servem aos propósitos expostos anteriormente.

Ao atentar para as considerações sobre a composição social brasileira, algumas das contribuições de Cândido P. F. de Camargo, um dos pioneiros nos estudos de sociologia da religião no Brasil, são colocadas em perspectiva a fim de dar conta das primeiras adaptações da religiosidade brasileira ao meio urbano, ocorridas nas primeiras décadas do processo de urbanização do Brasil.

Posteriormente, dou ênfase a elementos que caracterizam as religiosidades do cenário urbano da contemporaneidade brasileira e que vieram dimensionar o que foi concebido como mercado dos bens de salvação, salientando as suas marcas na paisagem das cidades. Dentre as reflexões derradeiras, e levando em conta o cenário de reprodução do pensamento mágico no espaço urbano, discuto algumas das razões pelas quais se afirma que, no Brasil, diferentemente de outras experiências ocidentais, o processo de urbanização se deu antes que um processo mais amplo de racionalização tivesse alcançado os diversos setores da experiência humana e social.

\section{Cidade e mentalidade mágica: a contribuição de Robert E. Park}

Ao estudar as relações entre magia e mundo urbano, uma das contribuições mais interessantes com que tive contato é a de Robert E. Park (1984), que, em seu trabalho Magic, mentality and city life, 
define o conceito de magia e suas manifestações numa cultura citadina específica das ilhas inglesas do Caribe ${ }^{2}$.

Baseado nessa experiência de pesquisa no Caribe, Park (1984) acreditava ser possível investigar, comparativamente, as mentalidades de grupos culturais diferentes, bem como descrever o processo por meio do qual diversos grupos sociais fazem a transição de um estágio cultural a outro. Numa conjuntura em que traços de modernidade marcavam a presença por meio da urbanização, Park indagava acerca de como as tradições de "mentalidade" mágica se ajustavam a esse equacionamento da vida tão afeito à modernidade e a uma "mentalidade racional". Embora recebendo claras influências de uma antropologia evolutiva que concebia os processos de mudança cultural pelas vias da passagem de estágios inferiores a outros superiores, colocava, desta feita, questões de pesquisa essenciais para a compreensão do encontro entre a tradição e a modernidade.

Nessa aproximação com a antropologia evolutiva, Park (1984) definia as categorias com as quais trabalhava contrapondo as noções de magia e de ciência, utilizando-se das contribuições de LévyBruhl $^{3}$. Seguia, assim, uma tradição bastante marcante nos delineamentos das ciências sociais da época ao se aproximar da magia como objeto de estudo. Para Park (1984), então, a magia aparece como um fenômeno particularmente humano, antigo e disseminado, destoando da ciência, a qual é concebida como manifestação social excepcional, muito recente, racional e, possivelmente, fortuita.

Seguindo, então, as orientações de Lévy-Bruhl, o qual descrevia a inteligência e os hábitos de pensamento dos "selvagens" como um tipo de mentalidade, Park compreende magia como um "tipo de mentalidade", sendo a mentalidade, por sua vez, forma de pensamento. A mentalidade dos povos primitivos - repetindo as nomenclaturas usadas por LévyBruhl e pela antropologia de então -, seria operada segundo um padrão "pré-lógico", pouco afeito às operações racionais e ao que os estudos de lógica chamam de operações discursivas do pensamento. Tal distanciamento das operações racionais, muito embora parecesse depreciar sociedades inteiras, não era entendido por Park como incapacidade ou deficiência no entendimento. Pelo menos era o que queria fazer crer.

Nesse entendimento, portanto, o pensamento mágico consiste numa tradição prevalecente entre os "selvagens" ou "povos de mentalidade menos complexa", que interpretam o mundo como um conjunto de incidentes e mudanças repentinas, inesperadas. Trata-se de uma maneira de pensar que em muito menor medida distingue as fronteiras entre a natureza e sobrenatureza, entre a realidade sensível e a suprassensível, entre o sagrado e o profano. Há, entre essas esferas, uma correspondência natural, a qual marca o cotidiano das sociedades de "mentalidade primitiva", no dizer de Lévy-Bruhl $(1922)^{4}$. Essas mesmas fronteiras se tornaram bem mais marcantes e distinguíveis para os componentes da moderna cultura ocidental.

Nesse quadro de formulação teórica, é visível o esforço com vistas a diferenciar o homem "selvagem" do homem "civilizado", salientando que o primeiro está tão envolvido com o pressentimento do mal e com a satisfação de suas necessidades imediatas, que mal tem tempo ou inclinação para observar a rotina que o envolve, muito menos para colocá-la em perspectiva. Ora, é justamente a percepção e a explicação de tal rotina que proporcionaram às ciências naturais um papel de previsão das consequências futuras da ação e, por conseguinte, da atitude a ser tomada hoje tendo em vista as necessidades de amanhã. Isso colocava a ciência ao lado do pensamento racional ou civilizado, como afirmava aquela antropologia do início do século XX.

Caminhando com as formulações teóricas de Lévy-Bruhl, é justamente a descoberta e a explicação

2 Nesse trabalho Park investiga a sobrevivência do Negro magic num contexto social que vivia processos de urbanização. Trata-se de parte dos seus estudos publicados em The city: suggestion for investigation of human behavior in the urban environment (PARK, 1984).

3 Sobretudo a obra La Mentalité Primitive, publicada originalmente em 1922.

4 Essa particularidade da mentalidade primitiva é descrita já no primeiro capítulo da obra de Lévy-Bruhl (1922, p. 19), nos seguintes termos: "La nature au milieu de laquelle il vit se présente à lui sous un tout autre aspect. Tous les objets et tous les êtres y sont impliqués dans un réseau de participations et d'exclusions mystiques : c'est elles qui en font la contexture et l'ordre [...] En fait, ce surnaturel est un facteur si constant dans sa vie, qu'il lui fournit une explication de ce qui arrive aussi rapide et aussi raisonnable que notre appel aux forces reconnues de la nature". 
da rotina, nos termos de causa e efeito, que deu nascimento ao que veio a ser chamado de pensamento racional. Portanto, para o "selvagem" haveria eventos, mas não hipóteses. Não haveria o que chamamos de fatos. Estes, como pontua Park (1984), são resultados de um tipo de pensar crítico e de um tipo de reflexão dos quais o homem "primitivo", anterior ao homem "civilizado", parecia ser destituído.

Por outro lado, num contexto social em que predomina o modern life thought, termo utilizado por Park (1984), um traço peculiar é que todas as nossas formas de comportamento herdadas tendam à racionalização. Ademais, torna-se característico da vida moderna que nada mais pode ser aceito meramente em função de padrões de autoridade. Toda a tradição fica sujeita ao olhar crítico. E, já salientando traços característicos das ideias da Escola de Chicago, acrescentava:

The reason the modern man is a more rational animal than his more primitive ancestor is possibly because he lives in a city, where most of the interests and values of life have been rationalized, reduced to measurable units, and even made objects of barter and sale. In the city - and particularly in great cities - the external conditions of existence are so evidently contrived to meet man's clearly recognized needs that the least intellectual of peoples are inevitably led to think in deterministic and mechanistic terms (PARK, 1984, p. 130, grifo nosso).

No entanto, nesse mesmo trabalho, Park (1984) salientava que todos estamos sujeitos a pensar segundo os termos da magia naqueles domínios de nossa experiência que ainda não passaram por um processo de racionalização ou naqueles setores em que nosso controle é incerto e incompleto. Ora, se somos levados a pensar de maneira mágica nos setores da experiência em que o controle é incerto e incompleto, em setores ainda não plenamente alcançados pelo "pensamento racional", não parece ser justamente no contexto da cidade, num contexto repleto de urbanidade, que o homem - e a sociedade - tenderia a refugiar-se na magia? Esse quadro de considerações da possibilidade de recorrência à magia na grande cidade parece ser ainda mais plausível se considerarmos uma sociedade tal qual a brasileira, que manifesta os processos de modernização ocidental de maneira parcial ou seletiva, segundo as formulações de Souza (2000). Além disso, a urbanidade brasileira vive de forma intensa e extremada os problemas próprios da vida urbana que mundialmente preocupam cientistas e processos decisórios no campo das políticas públicas, problemas que intensificam sentimentos de incerteza e incompletude.

Em meio a suas reflexões, fica evidente que Park se alia a uma descrição do "homem primitivo", contrapondo-a ao do homem civilizado: diferentemente deste, aquele vive num mundo muito diverso, no qual as forças a rodeá-lo são misteriosas e incontroláveis e onde a natureza lhe parece tão selvagem, romântica e imprevisível como seus próprios humores. Ocorre que características muito semelhantes são incorporadas pelas grandes cidades na contemporaneidade: as forças ao redor são misteriosas (todavia, de outra forma), assustadoras, incontroláveis e imprevisíveis. Ademais, as sociedades da cultura ocidental contemporânea, sobretudo aquelas que vivem nas grandes cidades, vivendo as contradições e os problemas próprios do mundo urbano, estão imersas em circunstâncias e condições que muito provavelmente levam os indivíduos a vislumbrarem também na magia uma possível solução para os problemas.

Como equacionar, então, o advento da urbanidade ao lado da reprodução das religiosidades mágicas que no Brasil têm tomado forma nas últimas décadas? Ao responder essa questão, ao mesmo tempo procura-se compreender de que maneira acomodou-se o modo de pensar tradicional (marcado pela magia) nos e entre os interstícios do processo de urbanização que o país experimentou. Refirome a um pensamento marcadamente mágico, que tem suas raízes na sociogênese do Brasil, como produto das interpenetrações simbólicas que nasceram do encontro de diferentes culturas desenraizadas.

\section{O advento da urbanização no Brasil e as primeiras mutações religiosas}

Principalmente a partir de 1940, com o processo de modernização do país, os fenômenos de imigração externa e graus diversos de urbanização parecem ter nítida influência na distribuição diferencial das religiões nos vários Estados do país. No que se 
refere ao grupo católico, verifica-se uma tendência de diminuição numérica, acentuando-se nas regiões mais urbanizadas e desenvolvidas do país. As vertentes umbandista-espírita e os pentecostalismos apresentaram-se como as novas concorrentes que, por meio de agressivo proselitismo, como aponta Camargo (1973, p. 24), disputaram a conversão de novos adeptos, recrutados nas classes sociais urbanas mais pobres, "suscetíveis de encontrar na solução sacral resposta ideológica a condições de sua existência".

Primeiramente, vale salientar que, ao longo das mutações do campo religioso brasileiro, desenvolveu-se um tipo de catolicismo "santorial" em cujo contexto salientam-se as festas e as devoções populares. Nesse contexto o culto aos santos tem um significado mágico nítido: busca por segurança, por boas colheitas e por saúde. Por outro lado, sobretudo nas áreas rurais, observa-se a ocorrência de modalidades de devoções distanciadas dos padrões da hierarquia sacramental católica, mas que eram toleradas pela igreja. A prática da pajelança era uma delas, a que se recorria principalmente para a cura de doenças. Essa prática, por sua vez, ocorria em íntima articulação com a tradição santorial do catolicismo rural. Há, por conseguinte, intensa interpenetração simbólica entre a cultura indígena e a tradição religiosa do catolicismo rural, o que torna mais expressivo na religiosidade do campo o tratamento mágico das doenças.

Nesse quadro de interpenetrações simbólicas as dimensões de tempo e espaço são influenciadas profundamente. No mundo rural alguns lugares, tais como igrejas e capelas, revestem-se de sacralidade, diante da qual os fiéis manifestam sua veneração. 0 altar, nesses ambientes sacralizados, ganha centralidade tal que passa a ser representado em outros espaços, mediante pequenos santuários nas estradas ou por meio dos oratórios nos lares privados.

A própria arquitetura das igrejas tem influência significativa na percepção do espaço, manipulando a orientação urbana. Além de atender aos interesses mágicos dos indivíduos, um catolicismo barroco proporcionava o movimento nesse espaço, mantendo sempre viva a dimensão mágica à disposição dos fiéis (SEVCENKO, 1998). E, nessa paisagem barroca, "a música, o canto, e a oratória do sermão se encarregarão de produzir essa atmosfera mágica em que as verdades da fé impregnam a alma pelos cinco sentidos, em meio à névoa perfumada do incenso" (MONTES, 1998, p. 104).

Tal concepção mágica do mundo predominante na vida rural só se transformou na medida em que contatos com a urbanidade conduziram à desorganização da composição social tradicional, levando os indivíduos a redefinirem seus valores, normas e papéis sociais. Ganhava espaço a visão profana da existência e difundiram-se valores leigos. 0 retrato que Camargo (1973) faz dessa transformação recebe nítidos traços de uma perspectiva funcionalista, pois entende que no contexto urbano diminuíam as funções sociais exercidas pelo catolicismo, bem como sua capacidade de influência sobre a conduta dos indivíduos, tendendo a restringir-se aos ritos de passagem, tais como o batismo e o casamento.

Desta feita, com conteúdo religioso empobrecido e funções sociais minimizadas, o catolicismo nas áreas urbanas do país tendeu a conservar-se como forma tradicional de religião, apresentando dimensões diversificadas em virtude da complexidade característica da vida urbana e do processo de mudança social que desencadeou. Todavia, mesmo apresentando tais dimensões diversificadas, sua capacidade de influenciar a conduta decresceu radicalmente em comparação com o catolicismo de tipo tradicional rural. Isso porque, ao lado das mudanças econômicas, demográficas e sociais, crescia uma visão dessacralizada do mundo. Evidentemente, essa dessacralização ocorreu mais em alguns domínios da existência do que em outros.

Porém, levando em conta os interesses da reflexão que faço aqui, um aspecto que chama a atenção é a "magnitude de envolvimento ritualístico" de que trata Camargo (1973, p. 62) em sua discussão da religiosidade no contexto urbano. Ao longo do processo de urbanização brasileira não há diminuição da busca pelos diversos serviços religiosos no contexto do catolicismo urbano. Muito embora predominasse uma concepção profana de orientação da vida, "em momentos de crise e tensão individual, conhecimentos, experiências e interpretações religiosas são reavivadas, trazendo explicações consoladoras e renovando o sentido da vida" (CAMARGO, 1973, p. 62).

Ao passo que a sociedade brasileira se urbanizava, parte do contingente urbano que migrou de áreas rurais para as grandes cidades industrializadas passou a viver a religião de um modo diferente do que predominava no contexto do catolicismo 
tradicional rural. Ao lado de certas sobrevivências do ritualismo do catolicismo rural, começava a tomar forma, de maneira ainda embrionária, a religião como serviço, à qual se recorria com vistas a suprir as diversas necessidades do cotidiano. Nesse contexto, a religião católica passava por vagarosa mutação em decorrência de sua adaptação ao mundo urbano. Ao lado dessa mutação, crescia o sucesso de outros segmentos religiosos, entre os quais se destacaram os pentecostais, os espíritas e os umbandistas.

Entre os indivíduos que migraram para a zona urbana, surgiam, portanto, expectativas e necessidades que o catolicismo tradicional rural deixava de atender. A complexidade da existência se ampliava. A quantidade de demandas, provenientes de distintos campos da vida social, aumentava significativamente no contexto urbano. Onde buscar elementos que viessem responder adequadamente a tais expectativas, que pudessem dar conta das novas demandas que se impunham de forma rápida e contundente?

A resposta mágica com vistas a atender a essas necessidades cada vez mais abundantes e diversificadas não foi proporcionada exclusivamente pelo catolicismo urbano. Na verdade, no período em questão, em muito menor medida o catolicismo conseguiu satisfazer magicamente essas novas necessidades, principalmente porque no mesmo momento em que uma urbanização vertiginosa tomava conta do país, o catolicismo se romanizava, tornando-se mais ortodoxo e menos afeito, por conseguinte, a práticas mágicas. Em outras palavras, um movimento de homogeneização do catolicismo operava com vistas a torná-lo mais próximo da ortodoxia de Roma, o que repelia e freava a reprodução das já tradicionais práticas mágicas sobreviventes desde a experiência colonial (OLIVEIRA, 1985).

Por conseguinte, as práticas mágicas que compunham o cotidiano da sociedade, nas bases do substrato simbólico sincrético do catolicismo tradicional rural, via-se, de repente, órfã, desgarrada. É preciso entender que a satisfação das necessidades diversas do cotidiano da população brasileira, desde o período colonial, era proporcionada de forma mágica pelo sincretismo religioso que se reproduzia sob o título de catolicismo popular. Então, ao romanizar-se, a partir de inícios do século XX, o catolicismo deixava de responder magicamente às demandas crescentes que a existência no mundo urbano impunha aos indivíduos. Abria-se, assim, espaço para outras heterodoxias religiosas.

No que se refere à tradição protestante representada por luteranos, presbiterianos, metodistas e batistas, muito timidamente começaram a aportar no Brasil no século XIX. Esses segmentos, em menor medida, propiciaram à população brasileira resposta sacral às necessidades cotidianas, sobretudo por serem mais fechados em sua ortodoxia. Convém salientar que a expansão religiosa da tradição protestante foi concomitante aos primórdios de mudança social no país, coincidindo com o advento da urbanização e da industrialização. Entretanto, "a compatibilidade historicamente predominante entre Catolicismo e tradições culturais do país já se encontrava sobremaneira solidificada quando grupos de imigrantes adeptos do Protestantismo organizaram suas primeiras comunidades religiosas" (CAMARGO, 1973, p. 127).

Alguns contingentes da classe média urbana, porém, menos acomodados aos padrões de dominação da sociedade estamental, viam surgir novas perspectivas nas ideias religiosas do protestantismo. Eram indivíduos que buscavam significado para a vida não mais encontráveis no catolicismo dogmático, litúrgico e canônico de então.

Só tardiamente, portanto, surgiram no cenário do país a teologia, o estilo de vida e a organização eclesiástica herdada dos reformadores. Sua ética puritana, enfatizando a honestidade nos negócios, a conduta austera e o recato no trajar, propugnava, como observou Camargo (1973, p. 137), "severas restrições de comportamento: não ter vícios, como o de fumar e beber; não frequentar diversões profanas; não participar de jogos de azar; não ter relações sexuais extraconjugais". Tal conjunto de formas de comportamento aproximava os conversos dos "estereótipos e padrões de respeitabilidade valorizados pela classe média urbana", transformando-se em "um dos veículos para a mobilidade social ascendente".

O movimento protestante via, portanto, desabrocharem algumas condições importantes para o seu desenvolvimento, principalmente com o advento da urbanização e as transformações socioeconômicas iniciadas na década de 30 . A classe média brasileira, no afã de sucesso e ascensão social, encontrava no 
"ethos" protestante o estímulo para desempenhar novos papéis, sancionados religiosa e moralmente.

Todavia, atente-se para o fato de que os processos de urbanização e mudança social são decorrentes, sobretudo, de aspirações cuja natureza é política e/ou socioeconômica. Em razão disso, era minoritária a parcela da população que, aderindo às principais ideias da tradição protestante, convertia-se aos seus princípios como norteadores da conduta cotidiana.

Cumpre salientar que, passadas as primeiras décadas de acomodação à cultura brasileira, também o protestantismo passaria por mutações diversas, de maneira que foi se adequando ao "ethos" da religiosidade popular, com seus traços barrocos e práticas mágicas. É em decorrência dessa acomodação que encontraram lugar as variações pentecostais, as quais passaram a se tornar expressivas desde a década de 1940.

Acentuando o esquema de proselitismo e nacionalização das igrejas, o pentecostalismo expandiu-se especialmente nos centros mais urbanizados, formando grandes comunidades religiosas. Um dos traços de seus esquemas proselitistas consistiu no emprego de recursos de comunicação de massa, o que intensificou sobremaneira sua capacidade de expansão, estabelecendo novas formas de ser religioso no espaço urbano: utilização das praças, de salas em centros urbanos, das ondas de rádio e de televisão, além da construção de templos com velocidade surpreendente. $\mathrm{O}$ estilo proselitista próprio da vertente pentecostal inaugurou no cenário religioso brasileiro as marcas do apelo constante à conversão, carregado de emoção, o qual inicialmente atingiu, sobretudo, as camadas mais pobres dos centros urbanizados.

Observe-se que a parcela da população que mais aderiu às novas igrejas tem a característica de ser proveniente de áreas tradicionais que sofreram processo de desorganização social, em decorrência do aparecimento de novas formas de produção, do rápido desenvolvimento das redes de comunicações e de comercialização no país, fenômenos estes característicos do processo de urbanização, os quais geralmente implicam redefinição da divisão do trabalho. Os novos integrantes das cidades se depararam com dificuldades profundas com vistas à acomodação aos novos padrões de vida da sociedade urbana, marcada por rápido processo de industrialização.
Tais dificuldades teriam encontrado refúgio no impacto do crescimento pentecostal, o qual preenchia "as necessidades e aspirações dos que se encontram envolvidos em processo acelerado de mudança sociocultural que não conseguem controlar" (CAMARGO, 1973, p. 148).

Com efeito, a adesão ao pentecostalismo permitiu o estabelecimento de contatos primários à maneira daqueles que predominavam nas configurações sociais próprias do mundo rural. Já no mundo urbano, por outro lado, os contatos são predominantemente secundários, uma vez que substituíam os primários ao longo do processo de crescimento das cidades, onde se estabeleceu a organização industrial e uma diferente distribuição da população. Houve substituição, portanto, de relações diretas, face a face, por relações indiretas nas maneiras segundo as quais os indivíduos se associavam (PARK, 1979).

Para melhor compreender o crescimento dos pentecostais nas grandes cidades é necessário examinar um pouco mais a natureza das relações secundárias que predominam no mundo urbano. Para isso, vale atentar para as observações de Wirth (1979), para quem os urbanitas dependem, evidentemente, de um número muito maior de pessoas para a satisfação de suas necessidades, encontrando-se, assim, associados a uma quantidade muito maior de organizações. Entretanto, tal dependência não se dá em relação a pessoas particulares, e sim aos serviços ou bens que os grupos organizados proporcionam. Desse modo, os contatos caracterizados como sendo secundários podem até ser aqueles face a face, mas geralmente são segmentários, transitórios e impessoais.

0 pentecostalismo, por sua vez, ao expandir-se no mundo urbano, tornava possível o restabelecimento de relações primárias, diretas, face a face, em estilo comunitário. Tais relações se manifestaram nos vínculos de cooperação e no auxílio mútuo encorajado no seio da congregação religiosa. Trata-se de um tipo de associação que permitia contatos pessoais e não transitórios, muito à maneira dos contatos primários predominantes no mundo rural. Já na década de 1960 surgiram análises do crescimento do pentecostalismo no meio urbano brasileiro. A exemplo disso, Emilio Willems (1967) atentava para esse traço das igrejas pentecostais que se multiplicavam nas cidades brasileiras e chilenas. Embora humildes, incapazes ou ignorantes, o convertido à 
nova fé sentia-se imediatamente útil, pois nele depositavam confiança, chamando-o de "irmão", alimentando a certeza de pertencer ao "povo de Deus".

Além do restabelecimento dos contatos primários, o advento do pentecostalismo no cenário nacional possibilitou um refúgio para aqueles que anteriormente utilizavam-se das práticas de benzimentos e simpatias, incluindo o manuseio, para fins mágicos, de ervas e plantas curativas muito conhecidas no mundo rural. Considerando a perspectiva teórica de Camargo (1973), o pentecostalismo desempenharia dois tipos de funções: a que leva à integração social e a de natureza terapêutica. Essas funções, por sua vez, teriam sido desempenhadas num contexto de práticas mágicas cujos traços mantinham afinidades com a tradição mágico-religiosa brasileira: orações com imposição de mãos sobre os doentes, unção com óleo, orações feitas em peças de roupas ou objetos, atividades executadas especialmente pelos que portavam os chamados "dons de cura", direcionadas aos diversos tipos de enfermidades físicas ou psíquicas.

Concebida por Camargo também nos termos da função social que desempenhou e como resposta sacral a alguns setores da população urbana brasileira, a umbanda se constituiu no contexto urbano como produto da incorporação de elementos da doutrina espírita e do ritual católico ao patrimônio cultural das religiões africanas. Nos termos das funções a partir das quais Camargo compreendia as religiões no contexto urbano, a umbanda surge desempenhando funções semelhantes às desempenhadas pelo pentecostalismo: função terapêutica e de integração do indivíduo na sociedade urbano-industrial. Destarte, não podia o desenvolvimento de tal religiosidade ser explicado simplesmente pela difusão e continuidade de traços e complexos culturais afro-brasileiros.

Assim foi que, eliminando alguns dos traços mais extravagantes ${ }^{5}$ das crenças e tradições provenientes da África, a umbanda surgia da incorporação, ao espiritismo kardecista - o qual chegara da França em fins do século XIX -, da tradição de culto aos ancestrais típica das religiões africanas, das crenças e tradições indígenas e de determinados valores e símbolos característicos da fé cristã. A umbanda emergia, dessa maneira, associando elementos da doutrina espírita e do ritual católico (preces, devoções e valores) ao patrimônio cultural das tradições indígenas e religiões africanas, especialmente do candomblé. Tendo sido formada inicialmente no Rio de Janeiro ao longo das décadas de 1920 e 1930, a umbanda se expandiu para os estados de São Paulo, Rio de Janeiro e Rio Grande do Sul, ampliando sobremaneira o número de adeptos ${ }^{6}$.

Utilizando-se da metáfora da doença (MONTERO, 1990), o efeito terapêutico do ritual da umbanda visa ao restabelecimento da harmonia nos níveis do corpo físico, social e astral nos fiéis e na clientela que se encontravam em busca de solução para os conflitos e problemas cotidianos. Usa o espaço de forma peculiar: a umbanda é uma das expressões religiosas que se manifestam num terreiro. A descrição de Camargo (1961, p. 43-44) coloca em perspectiva algumas das características gerais dos terreiros de umbanda que se multiplicaram em São Paulo dos anos 60, contribuindo para a composição das cores e formas que a cidade foi tomando:

O "terreiro" situa-se, de preferência, nos bairros periféricos de São Paulo. Localiza-se em um barracão, antiga garagem ou prédio especialmente construído. Fora do barracão há sempre um pequeno altar, que permanece trancado, dedicado a Exu. Essa medida é tomada para impedir que o deus, deixado livre, saia a praticar os seus malefícios. No "terreiro" propriamente dito, barracão com cerca de $50 \mathrm{~ms}^{2}$, há um altar, semelhante aos católicos. 0 "Orixá" guia do "terreiro" assume o lugar de destaque, sob a figura do Santo Católico

\footnotetext{
5 Prandi (1991, p. 49) se refere a tais traços como "elementos mais comprometidos com a tradição iniciática secreta e sacrificial", dentre os quais os sacrifícios de sangue.

6 O primeiro centro de umbanda teria sido fundado em meados de 1920, como dissidência de um kardecismo que repelia a influência de negros e caboclos, os quais seriam espíritos inferiores do ponto de vista de kardecistas mais ortodoxos. Instalando-se, em 1938, numa área central do Rio, outros centros de umbanda surgiriam. Em 1941 promoveu-se no Rio de Janeiro o Primeiro Congresso de Umbanda, do qual participaram umbandistas de São Paulo. Nesta cidade (São Paulo), o primeiro centro umbandista surgiu em 1930, chegando a mais de setenta em 1952, segundo registros de cartório. Prandi (1991) apresenta um estudo detalhado da formação da Umbanda levando em conta a utilização de elementos do Candomblé.
} 
correspondente. São Jorge, Nossa Senhora, São Cosme e São Damião são os Santos mais comuns que integram o altar, além do Cristo abençoando, de braços abertos. A par das imagens tradicionais da iconografia Católica, figuras de "Pretos Velhos" e "Caboclos", além de colares e enfeites, próximos à representação de Iemanjá, ornam o altar?

Os sincretismos visíveis na descrição acima possibilitam enxergar os sinais da contribuição desse segmento religioso para a operação da diversificação da esfera religiosa no meio urbano brasileiro. Tal contribuição ganha amplitudes ainda maiores se levado em conta o caráter da adesão aos seus cultos: normalmente não há abandono da religião anterior. Neste caso, não se estabelece necessariamente a incompatibilidade de visões religiosas de mundo que geralmente implicam a conversão, a troca de estruturas ordenadoras do mundo. Em grande parte dos casos, os adeptos e a clientela em questão continuam consumindo serviços religiosos da religião na qual nasceu. Permite-se, desta feita, um trânsito religioso mais intenso, sem compromissos compulsórios. Tais possibilidades davam forma a um dos atributos da esfera religiosa que se foi compondo: aquele da religião como produto que cada indivíduo consome segundo necessidades concretas do cotidiano.

De acordo com Camargo (1961), ao apresentar uma solução sacral, tal manifestação religiosa também atendia a demandas próprias de grandes populações urbanas no Brasil. Essas demandas são descritas da seguinte maneira por Montes (1998, p. 98), ao referir-se às condições socioeconômicas e culturais de meados do século XX:

o processo de metropolização da cidade que se acentua, o aumento da solidão do indivíduo num mundo cada vez mais sem referências fixas, a ausência de respostas institucionais, laicas e religiosas, às suas aflições, a influência da contracultura que se faz sentir em escala planetária, levando à busca, em culturas distantes e exóticas, de novos modelos de sociabilidade, novos sistemas de valores e uma nova espiritualidade, num mundo que começa a registrar sistemas de crise profunda.

Essa conjugação de fatores, entendidos como demanda de uma população crescente, expressam uma ausência de soluções antes existentes no meio rural. A respeito disso já falava Wirth (1979) ao afirmar que nas grandes aglomerações industriais novos ajuntamentos tendiam a substituir as antigas corporações e outros grupos tradicionais. Em meio às manifestações crescentes de grupos sindicais, políticos e culturais, também as manifestações de grupos religiosos permitiam a leitura, nas entrelinhas, de reivindicações, de demandas, de carências de setores da população urbana, sobretudo de seu contingente mais pobre ${ }^{8}$. Esse contingente em menor medida encontrava nas instituições tradicionais, sejam elas o Estado ou a Igreja, recursos para conter suas inseguranças e suprir as suas necessidades, em grande medida inexprimíveis.

Assim é que soluções mágicas para essas necessidades e inseguranças apresentavam-se como as únicas disponíveis em meio ao cenário caótico que se instaurava no contexto urbano, o que decorre do fato de que o processo de mudança social não chegava a afetar igualmente as diferentes camadas da população, levando a defasagens e incongruências nos níveis de sua efetivação. Ademais, o ajustamento e a reorganização da visão do mundo tornavam-se imprescindíveis num contexto em que se prescreviam como irrealizáveis - pelo menos para as camadas populacionais mais pobres - as perspectivas de redistribuição de renda e de compensação econômica e social decorrentes de uma mobilidade social vertical. Em parte é em razão disso que a dimensão sacral permanecia como fonte de inspiração valorativa e como forma de conhecimento, ao mesmo tempo em que diversas esferas da sociedade se secularizavam. Uma vez que a sociedade da forma em que está organizada não apresentava condições a fim de suprir os diversos estratos da população com serviços tais como os da medicina, por exemplo, era na solução sacral que o indivíduo avistava

\footnotetext{
${ }^{7}$ Esta é parte da descrição que Camargo faz do tipo de terreiro mais afastado do kardecismo, num continuum em que diferenças e nuanças aparecem em função do sincretismo operado.

8 Como salienta Camargo (1973, p. 172), “A imagem da Umbanda está associada à de grupo social com menor prestígio e seus adeptos encontram-se, via de regra, entre os estratos sociais de nível econômico mais baixo" - a realidade suburbana das cidades grandes.
} 
meios disponíveis para dar prosseguimento à sua sobrevivência, recorrendo-se a uma sempre viva possibilidade mágica.

Essas são algumas das direções nas quais se compôs parte das expressões religiosas brasileiras com o advento da urbanização. Uma impressão primeira que pode vir ao raciocínio lógico é de que tal percurso religioso de caráter acentuadamente mágico viria a ser, de alguma forma, refreado pelas vagas dessacralizantes, racionalizantes e secularizantes que acompanharam o processo de urbanização desde seus primórdios. Todavia, não é isso que acontece: tal percurso parece, na verdade, acentuar-se ainda mais, ganhando traços mágicos de maneira marcante, ao mesmo tempo em que ganham espaço significativos níveis de desenvolvimento tecnológico e de complexidade urbano-industrial, considerando o quadro dos países ocidentais que têm seu desenvolvimento mais tardio.

\section{Práticas mágicas, expressões religiosas e urbanidade na contemporaneidade brasileira}

Um olhar para a composição do cenário religioso brasileiro contemporâneo nos contextos urbanos chama a atenção para os traços mágicos que se metamorfosearam, manifestando-se de formas diversas. Ao pluralizar-se, a esfera religiosa equacionou-se de tal maneira que na sociologia da religião das últimas décadas surgiram diversas interpretações forjadas na noção de mercado. No fim da década de 1960, Berger (1985, p. 149) interpretou dessa forma a diversificação religiosa, ao colocar em perspectiva o crescente denominacionalismo americano:

a tradição religiosa, que antigamente podia ser imposta pela autoridade, agora tem que ser colocada no mercado. Ela tem que ser "vendida" para uma clientela que não está mais obrigada a "comprar". A situação pluralista é, acima de tudo, uma situação de mercado. Nela, as instituições religiosas tornam-se agências de mercado e as tradições religiosas tornam-se comodidades de consumo. E, de qualquer forma, grande parte da atividade religiosa nessa situação vem a ser dominada pela lógica da economia de mercado.
Entre os estudiosos do panorama religioso brasileiro atual é recorrente o termo mercado dos bens de salvação, do qual fazem parte igrejas gerenciadas como empresas. Os meios de comunicação de massa, por sua vez, são postos a serviço de um proselitismo concorrencial agressivo. As instituições religiosas apresentam-se menos afeitas ao rigor doutrinário e litúrgico, mantendo um sistema de crenças fluido, mais ou menos improvisado. Nessa conjugação de fatores torna-se maior a autonomia dos indivíduos, os quais se encontram em condição de escolher religião numa oferta em ampla expansão (MONTES, 1998).

É tamanha a diversificação das atividades, funções e formas de organização manifestadas pelas expressões religiosas nas grandes cidades, que a descrição de seu ajustamento ao espaço urbano mistura-se e opera à maneira dos muitos empreendimentos que surgem e se desenvolvem nas cidades. Isso descreveu bem Pierucci (1997, p. 253), ao listar as atividades nas quais as organizações religiosas passaram a exercer:

escolas, rádios, emissoras de televisão, editoras, livrarias, jornais e revistas, lojas de disco e vídeo, produção e comercialização de objetos religiosos e souvenirs, instituições financeiras, instituições de saúde, serviços de terapia religiosa, de aconselhamento psicoterápico, de atendimento paramédico, creches, orfanatos, hospitais, estruturas imobiliárias, construtoras, prédios de apartamentos e de escritórios, propriedades fundiárias de todo tipo e tamanho, ONGs, lobbies, empresas de marketing, etc., muitas delas, atividades econômicas sob o guarda-chuva da isenção fiscal por se tratar de organizações religiosas.

Parece que também a esfera religiosa é entregue ao modus operandi do mercado. No dizer de Simmel (1979, p. 14), a metrópole toma dimensões tais que a economia do dinheiro passa a dominá-la, numa composição social em que há "compradores inteiramente desconhecidos, que nunca entram pessoalmente no campo de visão propriamente dito do produtor". 0 caráter cada vez mais calculista da vida moderna, ocasionado em grande medida pela economia do dinheiro, parece esculpir as religiosidades brasileiras da contemporaneidade de forma a torná-las compatíveis com a linguagem e o modus vivendi característico do mercado. 
A religião torna-se produto, algo que se compra e que depende quase que exclusivamente do gosto do cliente, passando para o universo do privado, vindo a consistir, nas palavras de Montes (1998, p. 69), numa fluidez específica, num baixo grau de institucionalização das igrejas, proliferação das seitas, fragmentação de crenças e práticas devocionais; enfim, num "rearranjo constante ao sabor das inclinações pessoais ou das vicissitudes da vida íntima de cada um". Diferentemente da religião de outrora que, no Brasil, por quatro séculos fora indissociável da vida pública, atrelada que estava à estrutura de poder de Estado. A instituição do padroado, que sobreviveu até o fim do século XIX, era um produto dessa associação.

O novo pentecostalismo, que, por sua vez, despontou no cenário religioso das últimas décadas, apresenta importantes inovações. Acentuam-se o uso de instrumentos de evangelização que, noutros tempos, não eram convencionais. Refiro-me àqueles instrumentos voltados sobretudo à comunicação de massa, por meio do rádio, da TV, tendas de lona itinerantes, bem como as concentrações em praças públicas, ginásios de esporte e estádios de futebol. Essa é a nova face do pentecostalismo que, no campo específico da sociologia da religião, denominou-se neopentecostalismo (MARIANO, 1999). Essa nova expressão religiosa inovou, transformando o espaço urbano ao organizarem-se em cortejos festivos, juntando multidões, seja em lugares públicos abertos ou em suas edificações de grande porte, algumas das quais eram anteriormente teatros, cinemas, supermercados e galpões.

É fato surpreendente que, contemporaneamente, cinemas, teatros, supermercados, galpões e outras edificações de grande porte passem a servir a objetivos sacrais. Digo surpreendente porque, principalmente a partir do século XVII, na Europa, era da igreja que, ao som do brado secularização!, eram subtraídos a jurisdição e o controle eclesiástico de territórios e instituições (MARTELLI, 1995, p. 275). No mundo atual, em plena sociedade urbana, dita secularizada, são exatamente os espaços construídos sob os sustentáculos de um processo modernizador, urbanizante, racionalizante e secularizante que perdem a posse para um novo processo, em grande medida sacralizador e magicizante. Processo sacralizante e magicizante que, pelo menos para as igrejas Universal do Reino de Deus (IURD) e congêneres, é acompanhado de uma estrutura empresarial capitalista e mercadológica, elemento que é, também, em grande medida, fruto daquele processo modernizador citado anteriormente. Isso faz dessas igrejas neopentecostais expoentes da representação mesma da urbanidade: organização de forma centralizada, à maneira da corporação, englobando diversas empresas de diversos segmentos, incluindo o das telecomunicações, ampliando-se nos moldes do franchising.

Vale lembrar, ainda, que o que singulariza as igrejas neopentecostais no panorama evangélico é que são igrejas autóctones, isto é, nacionais, contando com líderes genuinamente brasileiros. Essa autoctonia é caracterizada também pelos tipos de símbolos e rituais que essas igrejas, em especial a IURD, intensamente agregam ao seu universo de significado sacral: a benção do sal, do copo-d'água, do óleo, das rosas, das roupas, dos documentos. Práticas que atualizam a herança mágica herdada das interpenetrações simbólicas abalizadas pelo catolicismo nos primeiros séculos da conjugação social brasileira.

Constituem essas igrejas neopentecostais verdadeira solução sacral para indivíduos cujo ritmo de vida e conjunto de imagens mentais, no dizer de Simmel (1979), fluem com velocidades extravagantes, intensificando os estímulos nervosos e os fundamentos sensoriais da vida psíquica. Esses citadinos do Brasil contemporâneo parecem não dar conta dos mecanismos de manutenção que, também no dizer de Simmel (1979, p. 12), "os protegem das correntes e discrepâncias ameaçadoras de sua ambientação externa". Não tendo condições para reagir "com a cabeça", reagem "com o coração". Desse modo, por meio de uma rede de sociabilidade à qual se integram os fiéis, inscreve-se, no contexto urbano, uma nova forma de pertencimento à cidade, por vias mágicas, rompendo as fronteiras entre o sensível e o suprassensível.

Considerando-se, especificamente, o catolicismo, onde se enquadraria nesse panorama religioso contemporâneo? Ora, é justamente quando o catolicismo começa a viver a crise de apelo à Teologia da Libertação, principalmente na sua vertente de movimentação social nos quadros das Comunidades 
Eclesiais de Base ${ }^{9}$, com seu marcante componente social e político, que vemos a emergência do neopentecostalismo reivindicando sua participação no cenário público. Ocorre que tal reivindicação também surge da vertente Católica Renovação Carismática (RCC), nascida nos EUA simultaneamente ao nascimento das CEBs, com perfil ideológico oposto ao gestado pela Teologia da Libertação.

Os carismáticos - como são conhecidos - caracterizam-se muito à semelhança dos neopentecostais, seja no que se refere à maneira de moldar o cenário urbano, seja nas práticas de orientação mágica que desempenham. Reúnem-se em grandes encontros anuais, os chamados cenáculos, que acontecem muito frequentemente, à semelhança da IURD, em ginásios e estádios. Em São Paulo, reunindo mais de cem mil pessoas, a RCC já alugou o estádio do Morumbi com vistas a demonstrar sua força. Vale salientar, também, o uso intenso dos recursos televisivos, com programações variadas. São enfatizadas as reuniões de cura e os dons divinos que os fiéis recebem, o que salienta o caráter mágico presente também nessa modalidade religiosa. Os carismáticos desempenharam, desta feita, importante papel com vistas à diversificação da oferta dos bens de salvação a que têm acesso diversos setores da população urbana, sobretudo aqueles que desejavam manter-se na matriz de religiosidade católica. Assim, esse segmento da Igreja Católica também adere ao modus vivendi do mercado, adequando-se a um ambiente cada vez mais calculista e cada vez mais marcado pelo anonimato (SIMMEL, 1979), ao mesmo tempo em que se busca um sentido de comunidade, uma convivência mais intimista.

Ora, tal reinvenção do sentido de uma fé íntima parece ter afinidades com os interesses mágicos dos indivíduos que habitam as cidades. É, na maioria das vezes, em busca da satisfação de suas necessidades cotidianas que estes indivíduos estão ao recorrerem às novas religiosidades comunitárias. Mais do que um sentido de comunidade, muito possivelmente são os valores do individualismo possessivo, conforme observado por Montes (1998), que parecem predominar nesse cenário. É, essencialmente, com a esfera privada que esses indivíduos parecem se preocupar. Com efeito, ao passo que o mercado dos bens de salvação se expande, mais a reprodução e recriação de religiosidades atendem à oferta de serviços numa sociedade que opera à maneira do mercado.

Nesse contexto de reprodução das possibilidades religiosas, a celebração festiva da tradição católica popular é reapropriada. $\mathrm{O}$ ato festivo barroco, atrelado às práticas mágicas herdadas dos primeiros séculos de interpenetração simbólica, é o que possibilita, na cidade, além destes tradicionais movimentos festivos, a convivência de uma miríade de expressões religiosas que se movem com a desenvoltura característica do mercado metropolitano.

Essa mesma miríade de expressões religiosas mistura-se à paisagem urbana de maneira a borrar e tornar elásticas as fronteiras entre o sagrado e o profano, entre o público e o privado, entre a esfera sensível e a suprassensível, entre a natureza e a sobrenatureza. A respeito disso a descrição feita por Montes (1998, p. 125-126) da paisagem urbana de Acari, no Rio de Janeiro, merece destaque:

Por toda parte, imagens pintadas de São Jorge, Ogum guerreiro, às vezes ao lado de um salmo da Bíblia, valendo em sua linguagem forte por um "fechamento de corpo". Também por toda parte, pintados de verde, maiores ou menores, os triângulos, sozinhos ou ao lado da sigla TC, marca do Terceiro Comando, que divide com o Comando Vermelho o controle do tráfico na Baixada. Num pequeno nicho, comum nessas favelas da região, perto do Cruzeiro, tal como nos vilarejos nordestinos onde se venera a figura do Padre Cícero, imagens de são Jorge e da escrava Anastácia, ao lado de uma foto de Tonicão. Na quadra de areia, zona

\footnotetext{
9 Sublinhe-se o advento das CEBs enquanto movimento social no cenário urbano brasileiro. Como salientam Prandi e Souza (1996, p. 68-69), "as Comunidades Eclesiais de Base (CEBs) começaram a surgir em diversos países da América Latina nos anos 60, portanto, a partir do Concílio Vaticano II, no qual a Igreja Católica redefiniu substancialmente sua orientação naquilo que afeta o dia a dia do católico, não somente em termos meramente ritualísticos e de doutrina espiritual, mas sobretudo no que diz respeito à maneira como o cristão deve colocar-se no mundo profano. Naquela década, os movimentos sociais, especialmente o feminismo e o ecopacifismo, emergiram com bastante vigor, compondo com a nova pastoral católica uma espécie de revisão de concepções políticas acerca da sociedade e do indivíduo que valoriza enfaticamente questões de igualdade e da justiça social. Nesse movimento, já não se pensa nem o indivíduo e nem a religião sem se questionar a sociedade, suas estruturas e seus valores".
} 
de lazer para o joguinho de futebol, o baile funk, mas também para as reuniões mais importantes da comunidade, mais uma vez São Jorge, próximo a um desenho de Bob Marley quase flutuando por sobre uma folha de Cannabis sativa, depois rabiscada por cima, disfarçada em almofada ou saco de batatas. No Coroado, sob uma coroa pintada de verde, dois antebraços, um branco, outro negro, mãos se apertando cerradas: dir-se-ia um conhecido símbolo de poder encontrado nas igrejas católicas, se não se soubesse que significam também o pó branco e a folha negra, na linguagem do tráfico, além de indicar a unidade da favela do Coroado e de Parque Acari, sob um comando comum. Numa parede lateral, uma bela paisagem de cartão-postal da baía de Guanabara, vendo-se nitidamente desenhados, ao lado do Cristo Redentor do Corcovado, o sambódromo e o Maracanã. Logo abaixo, um urubu vestido com a camisa do Flamengo e as insígnias do time. Ladeando a figura, imagens de Nossa Senhora Aparecida, de São Jorge e de São Jerônimo, Xangô justiceiro.

Uma paisagem que não está somente sob o signo da violência, mas também sob o signo da magia, do sagrado, do suprassensível, da sobrenatureza. Elementos estes que vão, inadvertida, ilógica e incoerentemente, ser trazidos junto à comunidade do Acari com vistas a uma tentativa de edificação do nomos ${ }^{10}$ deste agrupamento social. Este nomos, por sua vez, é edificado, como nos revela a paisagem urbana de Acari, sob as bases da proteção dos orixás e dos santos católicos, bem como pelo uso dos salmos bíblicos, os quais desempenham a função de amuletos da comunidade. Ao mesmo tempo, são, também, canais que possibilitam um sentido de pertencimento comum a todos os membros desta comunidade, integrando-os todos numa mesma condição: "de negros ou mestiços pobres, desvalidos e injustiçados, tendo que participar, cada um a seu modo, certo ou errado, da luta comum pela sobrevivência" (MONTES, 1998, p. 127).

0 mesmo pode-se observar no que se refere às religiões afro-brasileiras que, também apresentando solução sacral, desempenham importante papel com vistas aos contrastes, às tonalidades de estilo e modos de ser na cidade, esculpindo a vida urbana com formas e contornos peculiares:

Vestimentas ostensivamente coloridas, batas, gorrinhos e panos-da-costa em tecido africano, fios-de-conta de pedras e cerâmicas importadas, cabelos à moda "afro", de corte geométrico ou em dreadlocks, passam a ser exibidos nos terreiros por ocasião dos toques, e migram dali para a danceteria, a lanchonete ou o bar mais próximos, orgulhosamente fundidos com outros símbolos de afirmação de identidade étnica, numa época em que começam a surgir e depois consolidar-se os movimentos negros (MONTES, 1998, p. 149).

Importante é notar que, desse modo, interpenetram-se elementos de identidade étnica, de preservação cultural, de expressão religiosa e de movimentos político-sociais de afirmação étnica. Nesse emaranhado de cores fortes e contrastantes torna-se difícil situar o campo específico da religião, que parece mesclar-se a outras esferas da vida cotidiana, formando um imenso "bolo" de símbolos, de significados e significantes cuja excentricidade só se pode encontrar na vida urbana, o nicho por excelência dessa fusão, a qual se revela sob o signo da festa coletiva.

Assim é que também as festas, ao lado das novas igrejas, agem no contexto urbano de modo a recriar contatos, relações e solidariedades mais próximas daquilo que Park (1979) e Wirth (1979) classificaram como primárias, sendo mais características da vida rural. As festas parecem munir os indivíduos com ferramentas de apoio ou mesmo com armas de defesa a fim de conviverem com o clima de anonimato e de intensificação dos estímulos nervosos que a urbanidade acarreta (SIMMEL, 1979). Tal interpretação ajuda a compreender o tom festivo das religiosidades que irrompem na vida urbana do Brasil contemporâneo, por meio das incontáveis movimentações religiosas, proporcionando contextos de sociabilidade e de reciprocidade: caravanas para grandes reuniões em instalações de grande porte das cidades, retiros, bem

\footnotetext{
${ }^{10}$ Como salienta Berger (1985, p. 32), o nomos consiste numa ordem significativa, a qual "é imposta às experiências e sentidos discretos dos indivíduos. Dizer que uma sociedade é um empreendimento de construção do mundo equivale a dizer que é uma atividade ordenadora, ou nomizante".
} 
como as tradicionais romarias a Juazeiro do Padre Cícero, a Aparecida do Norte, a Bom Jesus da Lapa e a Pirapora.

Ao dispersarem-se em caravanas em direção ao encontro nas grandes festas, formando aquele conglomerado característico da vida urbana, esses contingentes da população urbana suprem a busca dos contatos primários que, no processo de urbanização, foram dissipados ao longo das diversas configurações sociais que foram se equacionando, principalmente a partir da década de 1930.

\section{Sobre a concomitância entre urbanização, racionalização e magia}

A seguir coloco em discussão traços marcantes que apontam para a especificidade da urbanização brasileira, considerando o quadro geral de sua experiência de modernização. A adaptação da sociedade brasileira ao advento da urbanidade se deu numa configuração distinta daquela que marcou a experiência dos países europeus. Refiro-me à experiência do processo de racionalização do Ocidente, levando em conta a realização primeira dos elementos característicos da modernidade ocidental. Considere-se, portanto, um modelo primevo, uma configuração social de referência em que se dá a urbanização. Esta, por sua vez, manteve-se ligada a um processo de racionalização ocidental aos quais os quadros diretivos da sociedade brasileira se basearam e se baseiam a fim de dar prosseguimento aos caminhos de sua modernização.

Na cultura ocidental, como se pode vislumbrar ao longo da história, as vagas de urbanização estiveram, via de regra, intimamente ligadas e, de algum modo, subordinadas ao processo, de dimensões bem mais extensas, de racionalização. Weber (2004) demonstrou isso de maneira bastante elucidativa na introdução do clássico $A$ Ética Protestante e o Espírito do Capitalismo. Além do mais, a motivação de Weber ao escrever sobre a cidade é, de fato, o processo de racionalização ocidental, como apontaram Bourdin e Hirschhorn (1985), ao afirmarem ser o estudo weberiano da cidade um estudo da significação e da função de um certo tipo de cidade europeia no processo de racionalização ocidental, uma tentativa de explicação das formas divergentes de evolução do capitalismo na antiguidade e na Idade Média e, ao mesmo tempo, uma pesquisa sobre as origens do mundo moderno.

Nesse mundo moderno em conjugação, a racionalidade agiu, num primeiro momento, na função de geração de significado (basicamente, a cultura) da sociedade Ocidental, passando a atingir todos os outros níveis: abastecimento (economia), segurança (política) e socialização (educação) (SCHLUCHTER, 1985). Na verdade, a partir de ascendente processo de racionalização, o que ocorre é a autonomia das esferas umas em relação às outras, começando pela autonomia da esfera econômica. A apoteose desse processo - de expansão da racionalidade e autonomização das diversas esferas da sociedade - dá-se justamente num cenário revestido de urbanidade: é a cidade marcada pela autonomia e pela autocefalia. Vale lembrar, como salientou Cox (1971, p. 11) na introdução de seu A Cidade do Homem (no original, The Secular City), o advento da civilização urbana e o colapso da religião tradicional são duas marcas da nossa era, bem como movimentos cujas relações são marcadamente íntimas: "a urbanização constitui uma mudança maciça na maneira de os homens viverem juntos e torna-se possível, na sua forma contemporânea, apenas com os avanços científicos e tecnológicos surgidos das ruínas das visões tradicionais do mundo".

Saliente-se que tal processo de racionalização, marcado não apenas pela crescente autonomização das esferas da sociedade, como também pela autonomização das consciências individuais, pela secularização e pela extirpação da magia (desencantamento do mundo), não acontece no Brasil no mesmo ritmo e com a mesma intensidade que aconteceu nos países europeus. 0 Brasil percorre uma experiência bastante distinta, desde sua sociogênese, uma vez que as práticas mágicas não foram erradicadas na mesma medida. Ao contrário, desde a experiência colonial, as práticas mágicas proliferaram abundantemente. E tinham mesmo que proliferar, pois tratava-se de magia de adaptação a um sistema pernicioso aos indivíduos que compunham a massa da população. 0 que havia de religião racionalizada (em alguma medida), por sua vez, era, em sua maior parte, decodificado para uma linguagem, uma gramática, uma semântica mágica. Somente a magia era digerível 
nos primórdios da sociedade brasileira, sobretudo porque somente ela saciava a sede de necessidades, de satisfação do desejo aqui e agora. Além do mais, a religião racionalizada e o modo religioso de se pensar (não mágico) não eram compatíveis com o mecanismo da empresa capitalista no Brasil colonial $^{11}$. As práticas mágicas consistiam em engrenagem importantíssima de tal mecanismo, como outros perceberam na época ${ }^{12}$. Permitiam o sincronismo e a convivência pacífica das funções básicas (SCHLUCHTER, 1985) dessa sociedade: abastecimento (economia), geração de significado (religião), segurança (política) e socialização (educação).

Não obstante, a sociedade brasileira se urbanizou. E se urbanizou com todas as propriedades de uma urbanização plena. Todavia, não em compatibilidade com as estruturas de significado e de sentido de outras experiências de modernização ocidental, uma vez que no Brasil se experimentou diferentemente os traços profundos do processo de racionalização do Ocidente. Como já salientamos, na experiência brasileira imperou a adaptação, ao meio urbano, de práticas mágicas cujo traço principal consistiu na satisfação de necessidades imediatas (do aqui e do agora).

É na atualização dessas práticas mágicas que entendo estar grande parte da elucidação sociológica dos papéis fundamentais que desempenham as religiosidades que hoje crescem e marcam a vida e a paisagem urbanas no Brasil contemporâneo. Religiosidades estas que, principalmente por serem profundamente mágicas, moldam-se ao tom e ao formato do mercado, dimensionando ostentosamente o mercado dos bens de salvação.

\section{Conclusão}

Considerando a contribuição de Park acerca da mentalidade mágica e suas relações com a cidade, procurei atentar para a sobrevivência e adaptabilidade, na vida urbana brasileira, de práticas mágicas herdadas de um longo processo histórico de interpenetrações simbólicas, de porosidades e contaminações mútuas entre diversas manifestações religiosas.

Ao longo das reflexões, afirmei que o processo de urbanização experimentado pela sociedade brasileira tem traços de especificidade que o distinguem das demais experiências ocidentais, especialmente as europeias. Dentre tais traços merece destaque o fato de que, no Brasil, a urbanização não se deu com a mesma relação íntima com o processo de racionalização ocidental, situação que ocorreu em experiências europeias. Procurei dar atenção à esfera religiosa, a qual em menor escala passou igualmente por um processo de racionalização, dando origem ao início do processo de secularização. A religião dita racionalizada (Protestantismo tradicional) chegou ao Brasil mais tarde e timidamente, já na gênese do processo de urbanização da sociedade brasileira, pouco conseguindo fazer expandir sua cosmovisão.

Desta feita, as religiosidades que se adaptaram ao processo de urbanização no país, fazendo emergir novas formas de religiosidade na cidade, trazem na sua essência a herança e a atualização de práticas mágicas presentes na tradição religiosa brasileira. Tais religiosidades, por sua vez, desempenharam os papéis terapêuticos e de integração de camadas populacionais mais pobres, pouco

\footnotetext{
${ }^{11}$ A religião histórica, transcendente, dualista, de salvação, possui a peculiaridade de dotar os indivíduos de psiquismos mais dados a raciocínios dialógicos, que dialogam com o mundo ao redor, que conversam com a realidade total, que buscam explicar a razão de ser das coisas dentro de uma única e coesa estrutura de sentido, de significado, de significantes. Contradições, ao se fazerem presentes no interior daquela composição social, constituiriam a própria ameaça do caos a um nomos (ordem) meticulosamente instituído. A persistência de focos que exprimissem tais cosmovisões na sociedade colonial era uma ameaça à ordem estabelecida. Isso porque cedo ou tarde trariam à tona as decorrências que todo desenvolvimento religioso faz emergir, tais como os anseios por libertação.

${ }^{12}$ Basta ver a obra de Antonil (2007, p. 103-104), Cultura e opulência no Brasil por suas drogas e minas, publicada primeiramente em 1711, acerca da percepção da importância, para o funcionamento do mecanismo da empresa colonial, das manifestações sincréticas marcadamente mágicas, especialmente entre os escravos: "Negar-lhes totalmente os seus folguedos, que são o único alívio do seu cativeiro, é querê-los desconsolados e melancólicos, de pouca vida e saúde. Portanto, não lhes estranhem os senhores a criarem seus reis, cantar e bailar por algumas horas honestamente em alguns dias do ano, e o alegrarem-se inocentemente à tarde depois de terem feito pela manhã suas festas de Nossa Senhora do Rosário, de São Benedito e do arago da Capela do Engenho...”.
} 
beneficiadas pelas benesses esperadas em razão da modernização do país.

Saliento, ainda, que a expansão do mercado de bens de salvação opera com uma desenvoltura bastante condizente com a natureza das práticas mágicas, gerando serviços, produtos, mercadoria. Nessa expansão, visível se faz a força do modus vivendi mercadológico, peculiaridade urbana fundamental que a tudo parece abarcar sob o seu signo, inclusive a forma segundo a qual os indivíduos da cidade mantêm suas cosmovisões, suas maneiras de ler o mundo que os envolvem. As religiosidades, bem como as diversas práticas mágico-religiosas que hoje constituem tal mercado, suprem os indivíduos com novos sentidos de existência na cidade, munindo-os com mais elementos com os quais resolvem seus problemas e satisfazem suas necessidades.

Essas reflexões ajudam a compreender a relevância de estudos que coloquem em perspectiva a esfera religiosa no mundo urbano, pois contribuem para elucidar as carências, as inseguranças e as reivindicações de camadas da população que, alijadas de um bem-estar social e de uma compreensão totalizante da existência na cidade, buscam, num amplo mercado mágico-religioso, as relações sociais de outros tempos idos, bem como as soluções que, magicamente, possam provê-los de significado a fim de defenderem-se das ameaças características da urbe.

\section{Referências}

ANTONIL, A. J. Cultura e opulência no Brasil por suas drogas e minas. São Paulo: EDUSP, 2007.

BERGER, P. L. 0 dossel sagrado: elementos para uma teoria sociológica da religião. São Paulo: Paulus, 1985.

BOURDIN, A.; HIRSCHHORN, M. (Org.). Figures de la Ville: autour de Max Weber. Paris: Aubier, 1985.

CAMARGO, C. P. F. Kardecismo e Umbanda. São Paulo: Pioneira, 1961.

CAMARGO, C. P. F. Católicos, protestantes, espíritas. Petrópolis: Vozes, 1973.

COX, H. A cidade do homem. Rio de Janeiro: Paz e Terra, 1971.
LÉVY-BRUHL, L. La mentalité primitive. Paris: Les Presses Universitaires de France, 1922.

MARIANO, R. Neopentecostais: sociologia do novo pentecostalismo no Brasil. São Paulo: Loyola, 1999.

MARTELLI, S. A religião na sociedade pós-moderna: entre secularização e dessecularização. São Paulo: Paulinas, 1995.

MONTERO, P. Umbanda. In: LANDIM, L. et al. Sinais dos tempos: diversidade religiosa no Brasil. Rio de Janeiro: ISER, 1990. p. 119-122.

MONTES, M. L. As figuras do sagrado: entre o público e o privado. In: SCHWARCZ, L. M. (Org.). História da vida privada no Brasil: contrastes da intimidade contemporânea. São Paulo: Companhia das Letras, 1998. p. 63-171.

OLIVEIRA, P. A. R. Religião e dominação de classe: gênese, estrutura e função do catolicismo romanizado no Brasil. Petrópolis: Vozes, 1985.

PARK, R. E. A cidade: sugestões para a investigação do comportamento humano no meio urbano. In: VELHO, 0. G. (Org.). 0 fenômeno urbano. Rio de Janeiro: J. Zahar, 1979. p. 26-67.

PARK, R. E. Magic, mentality and city life. In: PARK, R. E.; BURGESS, E. W. The city: suggestions for investigation of human behavior in the urban environment. Chicago: The University of Chicago Press, 1984. p. 123-141.

PIERUCCI, A. F. Interesses religiosos dos sociólogos da religião. In: ORO, A. P.; STEIL, C. A. (Org.). Globalização e religião. Petrópolis: Vozes, 1997. p. 249-262.

PRANDI, R. Os candomblés de São Paulo: a velha magia na metrópole nova. São Paulo: Hucitec; EDUSP, 1991.

PRANDI, R.; SOUZA, A. R. A carismática despolitização da Igreja Católica. In: PRANDI, R.; PIERUCCI, A. F. A realidade social das religiões no Brasil. São Paulo: Hucitec, 1996. p. 59-91.

SEVCENKO, N. A arte da fantasia. In: ARAÚJO, E. (Org.). 0 universo mágico do barroco brasileiro. São Paulo: SESI, 1998. p. 59-64.

SIMMEL, G. A metrópole e a vida mental. In: VELHO, O. G. (Org.). 0 fenômeno urbano. Rio de Janeiro: J. Zahar, 1979. p. 11-25. 
SCHLUCHTER, W. The rise of western rationalism: Max Weber's developmental history. Berkeley: University of California Press, 1985.

SOUZA, J. A modernização seletiva: uma reinterpretação do dilema brasileiro. Brasília: Ed. UnB, 2000.

WEBER, M. A ética protestante e o "espírito" do capitalismo. São Paulo: Companhia das Letras, 2004.

WILLEMS, E. Followers of the new faith: cultural change and the rise of the Protestantism in Brazil and Chile. Nashville: Vanderbilt University Press, 1967.
WIRTH, L. O urbanismo como modo de vida. In: VELHO, O. G. (Org.). 0 fenômeno urbano. Rio de Janeiro: J. Zahar, 1979. p. $90-113$.

Recebido: 18/09/2011

Received: 09/18/ 2011

Aprovado: $12 / 02 / 2012$

Approved: 02/12/2012 